\title{
22
}

\section{PRME WORKING GROUP ON GENDER EQUALITY}

\section{Reflections}

\section{Melissa S. Fisher, Ghada Howaidy and Gudrun Sander}

\subsection{Introduction}

The study of gender in management education and business research has become increasingly important over the past several decades. The 2011 creation of the PRME Working Group on Gender Equality reflects this growing interest. The group brings together an interdisciplinary and trans-professional community of academics, practitioners, policymakers, and activists. Collectively they bring attention to understanding local, national, and international systems of gender and power in business, such as patriarchy and capitalism. Beyond this, the group provides a forum for interdisciplinary scholarly exchange and support. It is a loosely connected group of scholars who discuss their respective research projects, careers, and trajectories with one another.

In the summer of 2020, three longtime members of the Working Group came together several times to share their individual and collective experiences with one another. Their zoom meetings presented opportunities to talk about the activities they engaged with the Working Group. They talked about their experiences building a global repository of resources 
for integrating gender into management and education, researching the United Nation's Women's Empowerment Principles (WEP), and contributing chapters to edited volumes on gender and business.

Over time, the three Working Group members - one from the United States, one from Switzerland, and one from Egypt - began sharing their individual stories about the impact of the Working Group on Gender Equality on their careers and research trajectories. Their discussions provoked them to consider how each of their individual professional biographies intersects with the almost decade old history of the Working Group on Gender Equality, as well as much longer local, national, and international histories of gender, power, and management. After several conversations, the three came to realize that telling their individual stories provides an entryway into understanding the impact of the Working Group on its member's career experiences, networking activities, and understanding of themselves as gender scholars in business.

The scholars also recognized that in spite of their cultural and national differences, they share some commonalities in their experiences: the growing realization of gender inequities in institutions from universities to corporations; the importance of creating local, national, and transnational networks of gender scholars like the PRME Working Group; and working together in such groups to build more diverse and inclusive workforces in business. Moreover, their own research, writing, and teaching are closely linked to the PRME's six working principles.

In recent years, gender and management scholars have drawn attention to experimental forms of writing about gender (Fisher et al., 2018) This includes autoethnography, an approach to research and writing that seeks to describe and analyze personal experience in order to understand cultural experience. Inspired by such recent works, this chapter comprises the three scholars' stories, linking their individual experiences to the history of the Working Group and broader histories of systems of gender and power, namely, patriarchy and capitalism. In what follows Gudrun Sander, researcher, consultant, and entrepreneur, writes about how her personal story is interwoven with her research on gender equality as a leadership task and how her benchmark studies and analyses support leaders to become more inclusive. Ghada Howaidy, manager and researcher, describes how her personal feminist consciousness inspired her to institutionalize advocating for women in leadership positions and a better understanding of broken masculinity. Cultural anthropologist Melissa Fisher 
then describes how she moved from research and writing about a relatively bounded "local" community, the first generation of Wall Street women, to studying global gender initiatives such as the UN Women's Empowerment Principles, to collaborating with women in finance and cinema on the first Hollywood film about Wall Street women.

\subsection{Gender equality as a leadership task needs gender- responsible management education (Gudrun Sander, PhD, University of St. Gallen, Switzerland)}

\subsubsection{Where my journey began}

After my high school education in a girls-only class, I studied business administration in Austria. The students in marketing and organization were quite mixed, around $40 \%$ of them were women. But something felt wrong: no female research assistants, no female professors and a deep unconscious consensus, that this is not right. Moreover, gender-related topics were not part of the curriculum and I was not very conscious about these complex interwoven mechanisms.

In 1989, I crossed the border and came to the University of St. Gallen in the eastern part of Switzerland, an even more traditional area. This bordercrossing and the even worse situation of women - a totally male-dominated business school with $16 \%$ female students at that time - turned out to be a catalyst for my research interest as well as my personal development. I became consciously aware of the gender role-expectations, the inequalities, and the discrimination. Hence, I wanted to understand the underlying causes, the institutional processes, structures, and power relations behind, and wrote my $\mathrm{PhD}$ thesis about women and men in management. A small group of female PhD students was my first and very important support network. We discussed the idea of gender-responsible management in the early 1990s. It was out of scope and not mainstream at all. My research questions were, "Do women need different structures? Do we need to reframe what we think is good management and good leadership practice? What kind of leadership and management enable more balanced leadership teams?"

This small network was on the one hand the seed for the now formalized gender- and diversity program we have at our university today and on the other hand the starting point of Swiss and global networks - like the PRMEGEWG or the Women's Empowerment Principles - I am engaged in today. 


\subsubsection{My focus today}

As a researcher and entrepreneur, my work is multifaceted. The interplay between cultural norms, institutional structures, and individual behavior is still my main research interest today - with the clear goal to have an impact on companies toward balanced leadership teams and inclusive workplaces. With my team of around 20 researchers and consultants, we work on a local level. We facilitate and support the dialogue among educators, students, businesses, government, media, and other stakeholders on critical issues related to diversity and inclusion, especially gender diversity. We facilitate for example the Diversity \& Inclusion Week of our university ${ }^{1}$ where we show our research impact in practice. At the Competence Centre for Diversity and Inclusion, we publish the Gender Intelligence Report for Switzerland ${ }^{2}$ annually, D\&I benchmarks ${ }^{3}$ for several industries as well as for universities, run in-depth data and wage analyses ${ }^{4}$ for companies, bring well-educated women back to business, ${ }^{5}$ work with managers on unconscious biases and support companies in designing, implementing, and/or evaluating D\&I strategies. We teach gender-related topics at all levels from bachelor to executive education, act as mentors and supervisors. We also contributed to two PRME Books (Nentwich \& Sander, 2015; Sander et al., 2020).

What helped me drive the agenda locally was the global PRME GEWG network. It gave me a context, a forum to share ideas, reflect on similarities and differences across nations/global regions, on challenges women are facing all over the world, and on what is special here in Switzerland.

\subsubsection{What I envision for the future}

Gender equality is a leadership task and implies cultural change. How can we implement a culture of inclusion and how can we drive this change? Change starts at the top of organizations, needs new process design and behavioral change. Transforming corporate cultures and teamwork will be my top priority for future projects. Solely adding more women or minorities to male-dominated cultures is not sustainable. With the rise of AI, digital transformation, and agile working, diversity and inclusion topics moved from nice-to-have-initiatives to the top of the strategic agenda of nonexecutive and executive boards of companies and public administrations. I want to use this momentum. Because inclusion and change imply 
reflections on responsible management and reframing leadership (PRME Principle 2 Values) as well as setting up new recruitment processes, performance evaluations, and promotion processes with the use of AI and new tools (PRME Principle 3 Method). Transforming a corporate culture or getting more women into leadership positions requires multiple interventions. With my team and together with students, HR and D\&I experts, policymakers, and managers we want to strengthen responsible management and responsible management education. PRME and GEWG are a valuable source for this endeavor.

\subsection{Gender matters to men as well (Ghada Howaidy, DProf, The American University in Cairo, Egypt)}

Over a five-year journey as a mature professional doctoral student in the UK, I came into my feminist consciousness and named my approach to agency as "bricolage." Opportunism, in a positive sense, enabled me to seize an organizational "moment" and articulate the institutionalization of the women on boards observatory in Egypt. This is not only about gender equality in my country but about disruptive social change that starts at the top of organizations. I seek to participate in changing the public discourse about whether women should work, and whether there are qualified women to serve in senior positions, into an awareness of the economic contribution of women in Egypt. Official statistics confirmed that women are the main provider for 30\% of Egyptian families. The baseline report of the Women on Boards Observatory for 2018 showed that 9\% of board seats in listed companies, the banking sector and public enterprises are already held by women. In 2019, this became 10\%. Ministry of Planning statistics also revealed that the unpaid labor of women in the care economy in Egypt amounts to EGP500 billion, which was equivalent to almost $8 \%$ of GDP.

As I worked at the local level, I related to the values, research, partnerships, and dialogue principles of PRME. I contributed a chapter about the Women on Boards Observatory in a GEWG book in 2016. I created a consortium of relevant institutions in Egypt who partnered to support the Women on Boards Observatory. In addition, I actively engaged in dialogue at the local and regional levels to promote Women on Boards by launching the 30\% Club MENA and partnering with The Boardroom Africa. ${ }^{6}$ 
Men represent 50\% of society, so their voice should not be ignored. I could not ignore the crisis of masculinity and how it also played a role personally, organizationally, and politically. Feminism gave women the language to describe their new constructed self. Strong and independent are in my mind positive attributes for women. Men do not have the language to describe their new role in society as partner and not only provider. I faced this in my family with my husband, father and brother. I faced it at work with male colleagues. I also faced it politically in a patriarchal system where the state was my "father" and "provider." While the regime in Egypt may appear progressive by having the largest number of women ministers and largest number of women in parliament, this is happening in a restrictive political atmosphere.

We can't have women's rights at the expense of broken masculinity. My feminism is about wholeness, personal wholeness through the alignment with values, organizational wholeness through the alignment with purpose, and societal wholeness through inclusivity.

Will a reconstruction of male identity from provider to partner change patriarchy? I would say the answer is yes and no. Patriarchy looks different and is experienced differently in the multiple contexts in which it thrives, both explicit and hidden. But our everyday choices, actions and conversations create and construct reality that is ever changing. Some elements of patriarchy will remain, some will change. Will it still be called patriarchy in retrospect after some time? Change is not linear, we don't know. However, if we believe that our everyday actions create reality then it is important to have the awareness and the language to create a better reality. Gender equality is a game changer for social justice and a better world. I don't want the men I love to be left behind.

\subsection{Collaborating on gender research and public outreach: a short biography (Melissa S. Fisher, PhD, visiting scholar, Institute for Public Knowledge, New York University)}

A commitment to gender equality has carried me throughout my journey as a feminist academic and activist. My interest in understanding the transformations in women's experiences in male-dominated professions began when I was a child in the 1970s, listening to my grandmother tell me stories 
about her own experiences as one of the only women at the University of Pennsylvania Law School in the 1920s. I also remember hearing my mother, as I grew up, speaking about women's rights, as well as visiting my father and grandfather at their law office in midtown Manhattan: there, while still in elementary school, I spoke to the sole female lawyer in the firm about her career. My interests in women and gender studies only grew during my time as an undergraduate at Barnard College. Ultimately, when I entered graduate school, all of these experiences led me to decide to study the pioneering first generation of women on Wall Street for my dissertation research at Columbia University. Powerful, elite women in finance during the 1990s was not a conventional research topic to undertake within the discipline of anthropology in the United States. In graduate school I was fortunate to find the academic support of a number of pioneering female academics in their own right and the support of members of the first cohort of Wall Street women who were interested in focusing attention on ender inequality in finance.

In 2012, I published my book Wall Street Women. It follows the pioneering group of women as they moved from modest career beginnings, holding jobs on the lowest levels of banks (in the 1960s and 1970s), to high-level positions in global finance and national politics (in the 1990s), and to new ventures in 21st-century philanthropy and the promotion of gender equality in the workplace on the global level. Notably Barbara Krumsiek, whom I met originally in 1994 working on Wall Street, had become the CEO of Calvert, a global leader in socially responsible and sustainable investing based in the Washington, D.C. area. In 2004 she and her firm created the first global code of corporate conduct focused on empowering women and on advancing and investing in women worldwide. Five years later the firm partnered with the UN Global Compact and UNIFEM to create the Women's Empowerment Principles. And I began a small research project on the formation of the WEP based on fieldwork at UN events and interviews.

Working in the assemblages of institutions, persons, and practices associated with the UN WEP altered my understanding of the purpose of feminist ethnography. It entailed a shift away from conducting fieldwork, and subsequently writing about a single, relatively bounded community: the first generation of Wall Street women. Attending UN WEP conferences composed of actors from academia, industry, and policy making, coming temporarily together in NYC, entailed the recognition that I was navigating 
a field in which others were already conducting research and, in some cases, making policy. This field included Patricia M. Flynn and Maureen A. Kilgour, two of the three founding members of the PRME Working Group on Gender Equality.

As I became a member of the PRME Working Group on Gender Equality, I came to the further realization that rather than exclusively research and write another ethnography, I could also collaborate with gender experts from different fields, like Flynn, Kilgour, and others. I became interested in creating new kinds of research projects, forms of knowledge, and novel ways of anthropologists dialoging with other gendered experts. I even wrote an article about these possible forms of collaboration (Fisher, 2012). Many other disciplines regularly engage in collaborative forms of work. Anthropologists still remain, even to this day, wedded to solely conducting fieldwork for a sustained period of time. Working with the PRME Group enabled me to envision alternative ways of working with others and the possibility of bringing anthropology into more of a sustained dialog with studies of gender in business and management education. My first task was contributing to the group's global repository on gender by creating a list of anthropological, sociological and historical research on gender and work, particularly in industry.

During the past eight years, I have continued to be involved in interdisciplinary communities and experimented with ways of partnering with women in industry, all in a collective effort to bring attention to gender issues in business. In the summer of 2014, for example, I received an email from a woman in my book whom I called Constance Burke (not her real name).

Melissa - I am introducing you to Sarah Thomas, a film maker who is making a film that focuses on Wall Street through the eyes/experience of women. I was recently introduced to her by a former (male) colleague at my firm, and I suggested to her that she should read your work and meet with you. "Constance"

Soon thereafter I met with Thomas and her coproducer Alysia Reiner in Thomas's Soho loft in in Downtown Manhattan about their indie film Equity - in the making. Shortly thereafter I became an advisor, informing Thomas and Reiner about Wall Street women's experiences. My expertise helped them to shape the movie's screenplay ultimately written by Amy Fox. I also connected the two actors-producers to one of the women in my 
book, Candy Straight, who became the film's executive producer and main investor.

In January of 2016 the rights to the film were bought by Sony Classics, and it opened first in the United States and then parts of Europe that summer. That spring, Straight and I brought the movie to financial firms, museums, and universities in the United States to show and to use it as a pedagogical tool to discuss gender in the workplace. In 2017, I was invited by the US Embassy in Berlin to conduct a week-long tour speaking with professional women throughout Germany. During my visit I showed Equity to spark a conversation about gender, money, and the issues women face moving up the corporate ladder, such as the glass ceiling. I have subsequently taught the film in a variety of courses including one on the culture of finance at NYU.

I read my involvement with Equity as an example of one way in which I have been inspired by the Working Group and PRME Principles to bring awareness of gender issues in business to the broader public. Specifically, with respect to Principle 5, I collaborate with women in finance and film to help bring attention to gender inequality in business. And with respect to Principle 6, Dialog, I engaged in various spaces of dialogs with the women to educate the broader public about the challenging issues women face in male dominated work environments, like finance.

Today I am engaged in a new project on gender and the rise of virtual work in the wake of the global pandemic. Still experimenting with ways of engaging in outreach, I have been holding webinars on the topic for various groups of professional women. As I look to the future, I hope to collaborate with other gendered experts, perhaps members of the PRME Working Group on Gender Equality, on how we can address gender inequities in both physical and virtual space.

\subsection{Conclusion}

We wrote this chapter amidst the global COVID-19 pandemic, realizing how technology and the media have enabled us to witness the scale and impact of the pandemic across the world in an unprecedented manner. We also realize that the pandemic has further revealed institutional and systemic vulnerabilities, especially those related to social justice, gender, and equality. This highlights the importance and relevance of global networks such as PRME and its Working Groups as a channel for collaboration to 
create a better world (Principles 1 and 2 purpose and values). Maureen, Patricia and Kathryn paved the way as cochairs of the gender equality Working Group, bringing us together, producing books and creating the repository of gender academic resources (Principles 3 and 4 method and research). In this chapter we each tell a part of our own story that shows how the personal is political; how the local links to the global; and how we inquire, institutionalize, create partnerships, engage in dialogue, articulate meaning, advocate action, and continuously create change (Principles 5 and 6 partnerships and dialogue).

\subsection{Summary of GEWG background}

\subsubsection{Background}

- At the March 2009 consultation on gender equality within the UN Global Compact Maureen Kilgour proposed a Gender Equality Working Group.

- The Women's Empowerment Principles were launched in 2010 and Maureen presented The UN Global Compact and Women's Human Rights paper at the international symposium "Corporate Social Responsibility in a Globalizing World."

- In January 2011 she again discussed the Working Group during a human rights webinar at PRME and got it going right away.

\subsubsection{Action and achievements}

- The GEWG has been actively involved in producing six PRME books, with one or more GEWG members serving as coeditors, and over 20 chapters written by GEWG members.

- Two PRME books were coedited by the three GEWG coordinators, Patricia M. Flynn, Kathryn Haynes, and Maureen A. Kilgour.

- Integrating Gender Equality into Business and Management Education: Lessons Learned and Challenges Remaining. Greenleaf Publishing, 2015.

- Overcoming Challenges to Gender Equality in the Workplace: Leadership and Innovation. Greenleaf Publishing, 2016.

- Four subsequent PRME books were collaborations with other PRME Working Groups. Coordinators from the GEWG (Patricia M. Flynn), 
the Anti-Corruption WG (Tay Keong Tan), and the Anti-Poverty WG (Milenko Gudić) served as coeditors for all four of the volumes noted below.

- Beyond the Bottom Line: Integrating Sustainability into Business and Management Practice, Greenleaf Publishing, 2017.

- Redefining Success: Integrating Sustainability into Management Education, Routledge, 2018.

- Global Champions of Sustainable Development, Routledge, 2020. (Jan.)

- Struggles and Successes in the Pursuit of Sustainable Development, Routledge, 2020. (July)

- The GEWD also created an easily accessible Global Repository of links and information to assist faculty (across a range of disciplines) in the integration of gender issues into management education.

- Officially launched the Gender Equality Repository at the 2012 PRME Global Forum, June 14-15, 2012, in Rio de Janeiro.

- Challenges for repository: platform problems, potential move to a new platform and integration with other Working Groups' resources.

\subsubsection{Administration}

- The three founding GEWG coordinators are Patricia M. Flynn, ${ }^{7}$ Kathryn Haynes, ${ }^{8}$ and Maureen A. Kilgour. ${ }^{9}$ Currently Patricia and Maureen remain coordinators.

\subsubsection{Future}

- New research and case studies to facilitate the integration of gender issues in management education.

- Global dissemination of knowledge on good practices and innovations that foster gender equality at the workplace.

- Identify the major gaps in the teaching and research materials available on gender issues in management education.

- Work with PRME to identify corporate signatories who may fund curriculum development and/or research in areas where gaps exist on gender equality, provide information on good practices and innovations in fostering gender equality at their workplaces, and offer their organization as the site of a potential case study. 


\section{Notes}

1 Available at: www.inclusion-tagung.ch

2 Availabe at: www.advance-hsg-report.ch

3 Available at: www.diversitybenchmarking.ch

4 Available at: www.we-pay-fair.ch

5 Available at: www.es.unisg.ch/wbb-en

6 Seemoreinformationat:https://business.aucegypt.edu/outreach/corporategovernance/women-boards-observatory

7 See more information at: https://faculty.bentley.edu/details.asp? uname= pflynn

8 See more information at: https://www.hull.ac.uk/staff-directory/kathrynhaynes

9 Seemoreinformationat:https://www.uwinnipeg.ca/experts-guide/maureenkilgour.html

\section{References}

Fisher, M. (2012) Wall Street Women. Durham, NC: Duke University Press.

Fisher, M., Villesche, F. et al. (2018) 'Towards a powerful queer-feminist writing', Ephemera: Theory and Politics in Organizations, Volume 18, issue 4. 201.

Nentwich, J. and Sander, G. (2015) 'Integrating gender and diversity in management education. Playing the paradox between "mainstreaming" and "context only". The University of St.Gallen's Gender and Diversity Teaching Programme'. In: Flynn, P., Haynes, K. and Kilgour, M. (eds.) Integrating Gender Equality into Management Education. Greenleaf Publishing, pp. 236-245.

Sander, G., van Dellen, B., Hartmann, I., Burger, D. and Keller, N. (2020) 'Inclusive Leadership: Overcoming unconscious biases in HR decisions'. In: Tan, T.K. Gudić, M. and Flynn, P. M. (eds.) Struggles and Successes in the Pursuit of Sustainable Development. Routledge/PRME, pp. 45-55. 